\title{
HPV Type-Specific Prevalence a Decade after the Implementation of the Vaccination Program: Results from a Pilot Study
}

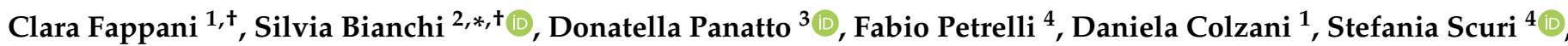 \\ Maria Gori $^{1}\left(\mathbb{D}\right.$, Antonella Amendola ${ }^{1,5}$, Iolanda Grappasonni ${ }^{4}\left(\mathbb{D}\right.$, Elisabetta Tanzi ${ }^{1,5}$ and Daniela Amicizia ${ }^{3}(\mathbb{D}$ \\ 1 Department of Biomedical Sciences for Health, University of Milan, 20133 Milan, Italy; \\ clara.fappani@studenti.unimi.it (C.F.); daniela.colzani@unimi.it (D.C.); mgorimaria@gmail.com (M.G.); \\ antonella.amendola@unimi.it (A.A.); elisabetta.tanzi@unimi.it (E.T.) \\ 2 Department of Health Sciences, University of Milan, 20142 Milan, Italy \\ 3 Department of Health Sciences, University of Genoa, 16100 Genoa, Italy; donatella.panatto@unige.it (D.P.); \\ daniela.amicizia@unige.it (D.A.) \\ 4 School of Medicinal and Health Products Sciences, University of Camerino, 62032 Camerino, Italy; \\ fabio.petrelli@unicam.it (F.P.); stefania.scuri@unicam.it (S.S.); iolanda.grappasonni@unicam.it (I.G.) \\ 5 Coordinated Research Center "EpiSoMI", University of Milan, 20133 Milan, Italy \\ * Correspondence: silvia.bianchi@unimi.it \\ + These authors contributed equally.
}

\section{check for} updates

Citation: Fappani, C.; Bianchi, S.; Panatto, D.; Petrelli, F.; Colzani, D.; Scuri, S.; Gori, M.; Amendola, A.; Grappasonni, I.; Tanzi, E.; et al. HPV Type-Specific Prevalence a Decade after the Implementation of the Vaccination Program: Results from a Pilot Study. Vaccines 2021, 9, 336. https://doi.org/10.3390/

vaccines 9040336

Academic Editor: Barbara Gardella

Received: 15 February 2021

Accepted: 30 March 2021

Published: 1 April 2021

Publisher's Note: MDPI stays neutral with regard to jurisdictional claims in published maps and institutional affiliations.

Copyright: (c) 2021 by the authors Licensee MDPI, Basel, Switzerland. This article is an open access article distributed under the terms and conditions of the Creative Commons Attribution (CC BY) license (https:/ / creativecommons.org/licenses/by/ $4.0 /)$.

\begin{abstract}
Human papillomavirus infection is a cause of the development of invasive cervical cancer. Three types of vaccine are currently available to prevent precancerous/cancerous lesions due to persistent infection, which is supported mainly by 7 different high-risk genotypes. The aim of this pilot study was to acquire preliminary data on type-specific prevalence 10 years after the implementation of the HPV vaccination program in Italy, in order to subsequently plan appropriate observational studies in the Italian population. First-voided urine samples were collected from 393 consenting subjects, both females and males, aged 18-40 years, and HPV DNA was detected by PCR amplification of a $450 \mathrm{bp}$ L1 fragment. All amplified products were genotyped by means of the Restriction Fragment Length Polymorphism (RFLP) method. The female population was divided into three cohorts ("vaccine-eligible", "pre-screening" and "screening" cohorts) according to the preventive intervention scheduled by age; males were included in the same three cohorts according to their year of birth. The overall prevalence of HPV infection was 19\%, being higher in females than in males $(22.1 \%$ vs. $13.6 \%, p=0.03729)$. In the female population, 10 years after the start of the national immunization program, we observed a reduction in the prevalence of vaccine types and the number of circulating genotypes, especially in the "vaccine-eligible" cohort. The frequency of HPV vaccine types increased with age, particularly in males in the "pre-screening" and "screening" cohorts. Our study highlights the importance of monitoring HPV infection in both genders, to validate the effect of the HPV vaccination program.
\end{abstract}

Keywords: HPV infection; urine samples; HPV genotype distribution; vaccine-preventable diseases; Italy

\section{Introduction}

It is well known that human papillomavirus (HPV) infection is the most common sexually transmitted infection worldwide [1,2]. Soon after their first sexual experience, the majority of women acquire the HPV infection, which is generally transient and resolves without symptoms. However, persistent infection can cause a wide range of diseases, including benign lesions, precancerous lesions and cancers, in both women and men [3].

HPVs are small, double-stranded DNA viruses that infect the mucosa and epithelium. More than 200 HPVs have been fully characterized [4,5] and are classified into low- and 
high-risk types according to their carcinogenic potential [6]. HPV DNA is found in almost $100 \%$ of cervical cancer samples, and there is a consensus that persistent high-risk HPV infection is a necessary cause of cervical cancer [7,8]. HPV types 16 and 18 are clear, powerful carcinogens and cause approximately $70 \%$ of invasive cervical cancers. HPV16 is also detected in about $90 \%$ of HPV-related anal, vaginal, vulvar, penile and oropharyngeal cancers [9].

The low-risk types, HPV 6 and HPV 11, are responsible for about $90 \%$ of anogenital warts and benign/low-grade abnormalities in the genital district [10], and are also associated with recurrent respiratory papillomatosis, a proliferative disease of the upper aerodigestive tract [11].

Before the introduction of HPV vaccination, periodic Pap testing in women aged $25-65$ years was the main way to prevent cervical cancer. Today, three prophylactic HPV vaccines targeting high-risk HPV types are available in many countries: 2-, 4- and 9valent vaccines. All these prophylactic HPV vaccines protect against HPV-16 and HPV-18. Furthermore, the 4-valent HPV (4vHPV) vaccine also protects against HPV-6 and HPV-11, and the 9-valent HPV (9vHPV) formulation also against HPV-31, HPV-33, HPV-45, HPV-52 and HPV-58 [12].

Data from recent surveillance systems and studies demonstrate that HPV vaccines are effective in preventing infection and diseases (vaccine efficacy $93 \%$ to $100 \%$ ) $[13,14]$ and the real-life effectiveness of HPV vaccines has become increasingly evident, especially in females vaccinated before exposure to HPV. However, the vaccines are also effective in subjects who are already sexually active.

More than 70 countries, including 33 belonging to the WHO European Region, have introduced HPV vaccination into their national immunization programs for girls, and 11 countries have done so for boys [15].

In 2007, Italy initiated a national immunization strategy of active call and free-ofcharge vaccination for girls aged 11-12 years [16,17]. Subsequently, in 2017, the strategy was extended to males aged 11-12 years (2006 cohort onwards) and at-risk subjects (men who engage in same-sex sexual behaviors) [17] following the latest evidence that HPV vaccination is also cost-effective in these target groups [16-18]. Furthermore, women aged 25 years who undergo cervical cancer screening are eligible for HPV vaccination, as recommended by the 2017-2019 National Vaccine Plan [17].

As yet, no comparison has been made between the prevalence of HPV before the introduction of the national HPV immunization program a decade ago and the current prevalence. The overall aim of the present study was to acquire preliminary data on typespecific prevalence 10 years after the implementation of the HPV vaccination program in Italy, in order to subsequently plan appropriate observational studies in the Italian population.

\section{Materials and Methods}

\subsection{Ethics Statement}

The study protocol, which was used by all research units, was approved by the Ethics Committee of the Liguria Region (LHU) Genoa, Italy (protocol n. 44/12). Written informed consent to participate in the study was obtained from all subjects.

\subsection{Study Population}

In accordance with the study protocol, we enrolled all consecutive eligible women and men aged 18-40 who spontaneously accessed sports medicine centers and universities located in three cities in different Italian Regions: Milan (Lombardy), Genoa (Liguria) and Camerino (Marche).

Females were divided into three cohorts according to their status regarding the prevention of HPV-related diseases: a vaccine-eligible cohort, which consisted of girls born between 1997 and 2001 and belonging to the first vaccination target cohort; a pre-screening cohort, comprising females born between 1991 and 1996, who were still too young to be 
called for a Pap test; and a screening cohort, consisting of girls born before 1990, who were eligible for a Pap test screening call.

Males were included in the different cohorts according to their years of birth. Recruitment was conducted between February 2017 and October 2019 and each participant was invited to provide an anonymous self-collected urine sample.

In Italy, the median age of sexual debut is 16 years in both sexes [19,20]. All participants in this study had already engaged in sexual activity. Indeed, being sexually active was an inclusion criterion.

\subsection{Sample Collection and Treatment}

First-voided urine samples were collected in sterile containers, kept at room temperature (RT) and processed within 6-8 h at each participating center. Briefly, $15 \mathrm{~mL}$ of each sample was centrifuged at $3800 \times g$ for $20 \mathrm{~min}$ at RT to obtain the cellular component. This phase was transferred to a new $1.5 \mathrm{~mL}$ collection test tube and centrifuged at $16,000 \times g$ for $15 \mathrm{~min}$ at RT. The pellet obtained was resuspended in $1 \mathrm{~mL}$ of PBS and aliquots were stored at $-20^{\circ} \mathrm{C}[21]$ until shipment to the center in Milan (Lombardy).

\subsection{DNA Extraction}

HPV DNA was extracted from $200 \mu \mathrm{L}$ of concentrated urine samples by means of the NucliSENS $^{\circledR}$ easyMAG ${ }^{\mathrm{TM}}$ automated (bioMérieux bv, Lyon, France) method in accordance with the standard protocol with off-board lysis. The concentration and purity of extracted DNA were evaluated by means of a spectrophotometer (Thermo Scientific NanoDrop 2000; Thermo Fisher Scientific, Inc., Wilmington, DE, USA). DNA quality was assessed by amplifying a $268 \mathrm{bp}$ (base pair) segment of the ubiquitous $\beta$-globin gene.

\subsection{HPV DNA Detection and Genotyping}

HPV DNA was detected through PCR amplification of a 450 bp L1 fragment by means of the degenerate primer pair ELSI-f and ELSI-r [21]. The amplification reaction conditions, after 5 min denaturation at $94{ }^{\circ} \mathrm{C}$, involved 40 cycles of amplification. Each cycle consisted of a denaturation step $\left(94^{\circ} \mathrm{C}\right.$ for $\left.30 \mathrm{~s}\right)$, an annealing step $\left(55^{\circ} \mathrm{C}\right.$ for $\left.30 \mathrm{~s}\right)$ and an elongation step $\left(72^{\circ} \mathrm{C}\right.$ for $\left.30 \mathrm{~s}\right)$. The last cycle was followed by a 7 min elongation step at $72{ }^{\circ} \mathrm{C}$. Each PCR run included positive (DNA extracted from HPV-16 positive cells, CaSki) and negative (water) controls. All amplified products were genotyped by means of the Restriction Fragment Length Polymorphism (RFLP) method, which is able to identify all HPV types present in the high-risk clade (HR-clade) and low-risk clade (LR-clade) of the alpha genus according to the latest IARC classification system (HR-clade, group 1: HPV-16, 18, 31, 33, 35, 39, 45, 51, 52, 56, 58, 59; group 2A: HPV-68; group 2B: HPV-26, 30, 34, 53, 66, 67, 69, 70, 73, 82, 85; LR types: HPV-6, 11, 28, 32, 40, 42, 43, 44, 54, 55, 57, 61, 62, 71, 72, 74, 81, 83, 84, $86,87,89)[22]$

\subsection{Sample Size Calculation}

The sample size was calculated according to data published by the HPV Information Centre [23], to estimate differences in the prevalence of HPV infection by age ( $<25$ and 25-44 years of age). Taking into account the lack of information on HPV infection in the general male population and the sexual transmission route, we considered an HPV prevalence in males comparable to that in females.

Overall, an estimated prevalence of $15 \%$ in males and females was considered: $18 \%$ in subjects aged $<25$ years and $11 \%$ in those aged $25-40$ years [23].

The sample size was calculated by means of the following formula, considering a $95 \%$ confidence interval $(95 \% \mathrm{CI})$ with an absolute precision of $\pm 5 \%$ :

$$
\text { Sample }=\frac{1.96^{2} \times H P V \text { prevalence estimated } \times(1-\text { HPV prevalence estimated })}{\text { absolute precision }{ }^{2}}
$$


The sample size of the overall population was estimated to be 196 subjects, for the population under 25 years was 227, and for those between 25 and 40 years of age was 150 subjects enrolled.

\subsection{Statistical Analysis}

As the HPV vaccination strategy was the same across the country, with no differences among regions, a comprehensive analysis was conducted.

Descriptive statistics (median and IQR) were applied to describe the entire study sample. HPV prevalence was expressed as a crude proportion with corresponding 95\% confidence intervals (95\% CI) and calculated by means of the Mid-p exact test, assuming a normal distribution. A $p$-value $<0.05$ was considered statistically significant (2-tailed test). Statistical analysis was performed by means of OpenEpi, version 3.01 [24].

\section{Results}

A total of 393 subjects participated in this study and provided an anonymous selfcollected urine sample. The study population included $253(64.4 \%)$ females and $140(35.6 \%)$ males and the median age was 23 years (range: 18-40). Of the 393 participants, 220 were recruited in Milan, 115 in Genoa and 58 in Camerino (Table 1).

Table 1. Baseline characteristics of patients enrolled from sports medicine centers and universities located in three cities in different Italian Regions: Milan (Lombardy), Genoa (Liguria), and Camerino (Marche) in Northern/Central Italy.

\begin{tabular}{ccccccc}
\hline & $\begin{array}{c}\text { Median Age } \\
\text { (IQR) }\end{array}$ & $\begin{array}{c}\text { Females } \\
\boldsymbol{N}(\mathbf{\%})\end{array}$ & $\begin{array}{c}\text { Males } \\
\boldsymbol{N}(\mathbf{\%})\end{array}$ & $\begin{array}{c}\text { Vaccine- } \\
\text { Eligible } \\
\text { Cohort } N(\mathbf{\%})\end{array}$ & $\begin{array}{c}\text { Pre-Screening } \\
\text { Cohort } \\
\boldsymbol{N}(\mathbf{\%})\end{array}$ & $\begin{array}{c}\text { Screening } \\
\text { Cohort } \\
N(\%)\end{array}$ \\
\hline Camerino $N=58$ & $23(22-24)$ & $25(9.9 \%)$ & $33(23.6 \%)$ & $3(6.3 \%)$ & $46(21.4 \%)$ & $9(6.9 \%)$ \\
Genoa $N=115$ & $21(20-22.5)$ & $115(45.5 \%)$ & 0 & $4(8.3 \%)$ & $99(46.1 \%)$ & $12(9.2 \%)$ \\
Milan $N=220$ & $27(22-33)$ & $113(44.7 \%)$ & $107(76.4 \%)$ & $41(85.4 \%)$ & $70(32.6 \%)$ & $109(83.8 \%)$ \\
Total & $23(21-29)$ & $253(64.4 \%)$ & $140(35.6 \%)$ & $48(12.2 \%)$ & $215(54.7 \%)$ & $130(33.1 \%)$ \\
\hline
\end{tabular}

Of the 393 participants, 75 (19.08\%, 95\% CI: 15.43-23.2) tested HPV DNA-positive: 56 of the 253 (22.13\%, 95\% CI: 17.34-27.56) females and 19 of the $140(13.57 \%$, 95\% CI: 8.62-20.01) males $(p=0.03729)$.

No difference in HPV prevalence was observed among the female subjects in the different cohorts, while an increase in positivity was observed in males: from $0 \%$ in the vaccine-eligible cohort to $12.28 \%$ in the pre-screening cohort and $19.67 \%$ in the screening cohort. HPV prevalence rates between the sexes and across cohorts are reported in Table 2.

Table 2. Prevalence of positive subjects, broken down by gender and cohort: vaccine-eligible cohort (born between 1997 and 2001), pre-screening cohort (born between 1991 and 1996) and screening cohort (born before 1990). A significant $p$-values are indicated in bold (significance considered $p<0.05$ ).

\begin{tabular}{|c|c|c|c|c|c|c|c|}
\hline \multirow[b]{2}{*}{ Cohort } & \multicolumn{2}{|c|}{ Males } & \multicolumn{2}{|c|}{ Females } & & \multicolumn{2}{|c|}{ Total } \\
\hline & $\begin{array}{c}\text { HPV- } \\
\text { DNA+/N } \\
(\%)\end{array}$ & $95 \%$ CI & $\begin{array}{c}\text { HPV- } \\
\text { DNA+/N } \\
(\%)\end{array}$ & $95 \%$ CI & $p$ & $\begin{array}{c}\text { HPV- } \\
\text { DNA+/N } \\
(\%)\end{array}$ & $95 \% \mathrm{CI}$ \\
\hline Vaccine-eligible & $0 / 22$ & $0.0-12.73$ & $6 / 26(23.08)$ & $9.92-41.95$ & 0.01876 & $6 / 48(12.50)$ & $5.86-24.70$ \\
\hline Pre-Screening & $7 / 57(12.28)$ & 5.53-22.79 & $\begin{array}{l}36 / 158 \\
(22.78)\end{array}$ & $16.75-29.81$ & 0.08748 & $43 / 215(20.0)$ & 15.06-24.19 \\
\hline Screening & $12 / 61$ (19.67) & $11.12-31.05$ & $14 / 69(20.29)$ & 12.04-30.99 & 0.9338 & $26 / 130(20.0)$ & $13.79-27.53$ \\
\hline Total & $\begin{array}{l}19 / 140 \\
(13.57)\end{array}$ & $8.62-20.01$ & $\begin{array}{l}56 / 253 \\
(22.13)\end{array}$ & $17.34-27.56$ & 0.03729 & $\begin{array}{l}75 / 393 \\
(19.08)\end{array}$ & $15.43-23.2$ \\
\hline
\end{tabular}

Of the 75 HPV DNA-positive samples, 4 (5.33\%) were not typable (NT). Overall, 111 different infections sustained by 34 different genotypes were identified. A single genotype 
was detected in $71.83 \%(51 / 71$; $95 \%$ CI: 60.56-81.35) of the HPV DNA-positive samples, and $74.51 \%$ (38/51; 95\% CI 61.28-85.03) of the genotypes identified belonged to the HR clade. The remaining 20 HPV DNA-positive urine samples (28.17\%; 95\% CI 18.65-39.44) showed multiple infections, and 95\% (19/20; 95\% CI: 77.72-99.75) of these were sustained by at least one genotype belonging to the HR clade. Multiple infections were detected in 16 of 56 (28.57\%) infected females and in 4 of $19(21.06 \%)$ infected males. HPV infections and HPV infecting types, broken down by the three different cohorts, are shown in Table 3. No difference among the cohorts was observed with regard to the prevalence of HPV infections, the frequency of multiple and single infections, or the prevalence of any type. The type-specific HPV prevalence in the 393 subjects, broken down by cohorts, is shown in Figure 1.

Table 3. HPV infections and HPV infecting types, broken down by cohorts: vaccine-eligible cohort (born between 1997 and 2001), pre-screening cohort (born between 1991 and 1996) and screening cohort (born after 1990).

\begin{tabular}{|c|c|c|c|c|c|c|}
\hline \multicolumn{7}{|c|}{ HPV DNA-Positive Subjects } \\
\hline & \multicolumn{2}{|c|}{ Vaccine-Eligible Cohort, $N=6$} & \multicolumn{2}{|c|}{ Pre-Screening Cohort, $N=43$} & \multicolumn{2}{|c|}{ Screening Cohort, $N=26$} \\
\hline HPV Infections & $\mathbf{N}(\%)$ & $95 \% \mathrm{CI}$ & N (\%) & $95 \% \mathrm{CI}$ & $\mathbf{N}(\%)$ & $95 \%$ CI \\
\hline Single infections & $3(50.0)$ & $14.66-85.34$ & $28(65.11)$ & $50.08-78.17$ & $20(76.92)$ & 58.05-90.08 \\
\hline Multiple infections & $3(50.0)$ & $14.66-85.34$ & $15(34.88)$ & $21.83-49.92$ & $2(7.69)$ & $1.31-23.16$ \\
\hline NT & 0 & 0-39.3 & 0 & $0-6.73$ & $4(15.38)$ & $5.09-33.06$ \\
\hline \multicolumn{7}{|c|}{ Total Number of HPV Infections } \\
\hline & \multicolumn{2}{|c|}{ Vaccine-Eligible Cohort, $N=16$} & \multicolumn{2}{|c|}{ Pre-Screening Cohort, $N=71$} & \multicolumn{2}{|c|}{ Screening Cohort, $N=24$} \\
\hline $\begin{array}{l}\text { HPV Infecting } \\
\text { Types }\end{array}$ & $\mathbf{N}(\%)$ & $95 \%$ CI & $\mathbf{N}(\%)$ & $95 \%$ CI & $\mathbf{N}(\%)$ & $95 \% \mathrm{CI}$ \\
\hline HR Group 1 & $5(31.25)$ & $12.46-56.32$ & $32(43.66)$ & $32.49-55.34$ & $15(62.5)$ & $15.81-38.3$ \\
\hline HR Group 2 & $3(18.75)$ & $5.00-43.01$ & $13(18.31)$ & $10.58-28.58$ & $6(25)$ & $5.10-21.82$ \\
\hline $\begin{array}{l}\text { LR Group } 3 \text { and } \\
\text { other LR types }\end{array}$ & $8(50.0)$ & $28-7226.59-73.41$ & $26(36.62)$ & $26.05-48.26$ & $3(12.5)$ & $3.28-30.36$ \\
\hline
\end{tabular}

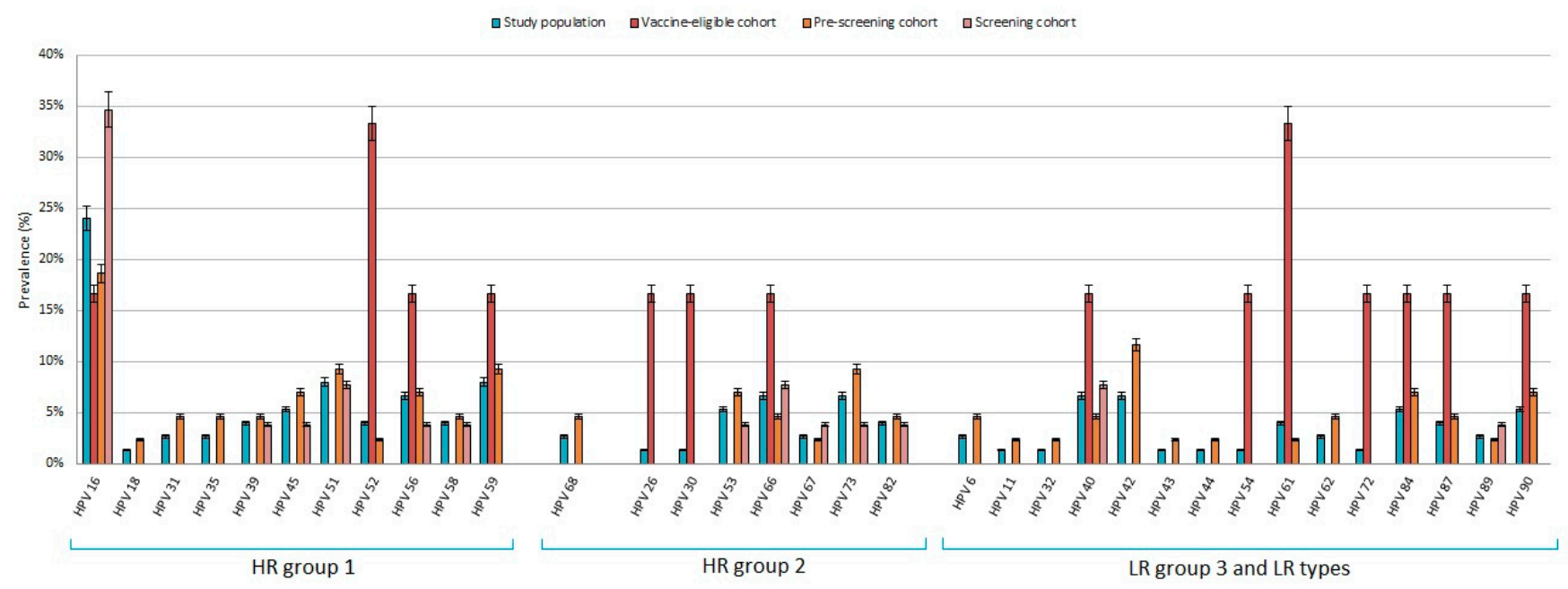

Figure 1. Type-specific prevalence with $95 \%$ confidence intervals in urine samples from 393 subjects, broken down by cohorts: vaccine-eligible, pre-screening and screening cohorts.

The numbers of HR and LR types observed were lower in the vaccine-eligible cohort than in the pre-screening and screening cohorts, though HPV-26, HPV-30, HPV-54 and HPV-72 were only detected in this cohort and a higher prevalence of HPV-52, HPV-56 and HPV-59 was observed. 
The prevalence of vaccine types was lower in the vaccine-eligible cohort than in the other cohorts. Indeed, the frequency of HPV vaccine types was significantly lower in the vaccine-eligible cohort than in the screening cohort $(p=0.02931$, Table 4$)$. The frequency of HPV vaccine types, regardless of vaccine formulation, increased with age, particularly in the male population belonging to the pre-screening and screening cohorts.

Table 4. Proportion of subjects free from high-risk HPV vaccine types (2-, 4- and 9-valent vaccines) broken down by cohort and gender.

\begin{tabular}{|c|c|c|c|c|c|c|}
\hline \multicolumn{7}{|c|}{ Study Population } \\
\hline $\begin{array}{c}\text { Proportion of } \\
\text { Uninfected Subjects }\end{array}$ & \multicolumn{2}{|c|}{$\begin{array}{c}\text { 2vHPV } \\
\text { (HPV-16 and HPV-18) }\end{array}$} & \multicolumn{2}{|c|}{$\begin{array}{c}\text { 4vHPV } \\
\text { (HPV-16, HPV-18, HPV-6 and } \\
\text { HPV-11) }\end{array}$} & \multicolumn{2}{|c|}{$\begin{array}{c}\text { 9vHPV } \\
\text { (HPV-16, HPV-18, HPV-31, } \\
\text { HPV-33, HPV-45, HPV-52, } \\
\text { HPV-58, HPV-6 and HPV-11) }\end{array}$} \\
\hline Cohort & $N(\%)$ & $95 \%$ CI & $N(\%)$ & $95 \%$ CI & $N(\%)$ & $95 \% \mathrm{CI}$ \\
\hline Vaccine-eligible, $N=48$ & $47(97.92)$ & $89.1-99.63$ & $47(97.92)$ & $89.1-99.63$ & $45(93.75)$ & 83.17-97.85 \\
\hline Pre-screening, $N=215$ & $206(95.81)$ & $92.24-97.78$ & $203(94.41)$ & $90.5-96.78$ & $195(90.70)$ & 86.07-93.9 \\
\hline Screening, $N=130$ & $121(93.08)$ & 87.37-96.32 & $121(93.08)$ & 87.37-96.32 & $119(91.54)$ & $85.48-95.21$ \\
\hline \multicolumn{7}{|c|}{ Female Population } \\
\hline $\begin{array}{c}\text { Proportion of } \\
\text { Uninfected Females }\end{array}$ & \multicolumn{2}{|c|}{ 2vHPV } & \multicolumn{2}{|c|}{ 4vHPV } & \multicolumn{2}{|c|}{ 9vHPV } \\
\hline Cohort & $N(\%)$ & $95 \%$ CI & $N(\%)$ & $95 \% \mathrm{CI}$ & $N(\%)$ & $95 \%$ CI \\
\hline Vaccine-eligible, $N=26$ & $25(96.15)$ & $81.11-99.32$ & $25(96.15)$ & 81.11-99.32 & $23(88.46)$ & 71.03-96 \\
\hline Pre-screening, $N=158$ & $151(95.57)$ & $91.14-97.84$ & $148(93.67)$ & $88.74-96.53$ & $142(89.87)$ & $84.18-93.67$ \\
\hline Screening, $N=69$ & $66(95.65)$ & $87.98-98.51$ & $66(95.65)$ & $87.98-98.51$ & $66(95.65)$ & $87.98-98.51$ \\
\hline \multicolumn{7}{|c|}{ Male Population } \\
\hline $\begin{array}{c}\text { Proportion of } \\
\text { Uninfected Males }\end{array}$ & \multicolumn{2}{|c|}{ 2vHPV } & \multicolumn{2}{|c|}{ 4vHPV } & \multicolumn{2}{|c|}{ 9vHPV } \\
\hline Cohort & $N(\%)$ & $95 \%$ CI & $N(\%)$ & & $N(\%)$ & $95 \%$ CI \\
\hline Vaccine-eligible, $N=22$ & $22(100)$ & $85.14-100$ & $22(100)$ & $85.14-100$ & $22(100)$ & $85.14-100$ \\
\hline Pre-screening, $N=57$ & $55(96.49)$ & 88.08-99.03 & $55(96.49)$ & 88.08-99.03 & $53(92.98)$ & $83.3-97.24$ \\
\hline Screening, $N=61$ & $55(90.16)$ & $80.16-95.41$ & $55(90.16)$ & $80.16-95.41$ & $53(86.89)$ & $76.2-93.2$ \\
\hline
\end{tabular}

\section{Discussion}

Human papillomavirus is the most common sexually transmitted infection worldwide. The Centers for Disease Control and Prevention (CDC) estimate that at least half of all sexually active individuals will acquire HPV at some point in their lives and that at least $80 \%$ of women will acquire an HPV infection by the age of 50 [25].

While most HPV infections do not cause symptoms and resolve spontaneously, persistent infection may lead to the development of a range of conditions of the reproductive tract, including precancerous lesions that may progress to cancer, both in women and men.

Human papillomavirus is a necessary (but not sufficient) cause of invasive cervical cancer. Three vaccines (2-valent, 4-valent and 9-valent) with prophylactic indications are currently available to prevent precancerous lesions and cancers due to persistent infection supported by up to 7 different high-risk genotypes (HPV-16, HPV-18, HPV-31, HPV-33, HPV-45, HPV-52, HPV-58). The 4-valent and 9-valent vaccines also offer protection against genital warts and low-risk lesions caused by HPV-6 and HPV-11 [12].

Since 2008, HPV vaccination has been offered free of charge to 12-year-old girls in Italy, and $70.6 \%$ of eligible subjects belonging to the first vaccinated cohort (females born in 1997) have received at least one vaccine dose [26]. The high coverage rate of HPV vaccination has been shown to impact on HPV-related diseases, reducing the burden of HPV infection, genital warts and cervical disease [27-30]. 
In the present study, the prevalence of HPV infection was evaluated in urine samples collected in 2017-2019 from subjects of both sexes. Cervical brushing still is the gold standard for HPV detection; indeed, a partial discordance between paired urine and cervical samples was observed in PCR-based genotyping results. Nevertheless, urine sampling is a highly sensitive method and a viable alternative to cervical brushing in women and urethral swabs in men, in order to detect and characterize HPV infection. Moreover, urine sampling is easy to carry out and offers the unquestionable advantage of non-invasiveness and the possibility of reaching a high adherence rate among women, men and vulnerable populations in the youngest age groups. Therefore, several studies have suggested that urine-based HPV detection is a suitable and effective tool for both epidemiological surveillance and screening [21,31].

The worldwide prevalence of HPV among women with no evidence of cervical lesions has been estimated at around 12\% [32]. Our results showed an HPV prevalence of $22.1 \%$ in women aged 18-40 years, which is higher than that reported in the pre-vaccination era in the same area $(14.3 \%)[33,34]$, with no significant differences among cohorts $(23.1 \%$ in vaccine-eligible, $22.9 \%$ in pre-screening, and $20.3 \%$ in screening cohorts).

To date, few data are available on the epidemiological status of HPV infection in males without clinical manifestations. A review published prior to the introduction of HPV vaccination in men found an HPV prevalence among sexually active men ranging from $1 \%$ to $84 \%$ worldwide. In a study of men aged 19-82 years (median age 46 years) from Brazil, Columbia, Thailand, the Philippines and Spain, the HPV prevalence was 16\% [35]. In the European low-risk population, the highest prevalence (34\%) was observed in Denmark, while in Italy the overall prevalence was 9\% [35]. Our data, collected from 140 men aged $18-40$ years, showed an overall HPV prevalence of $13.6 \%$, with higher values in those male cohorts other than the vaccine-eligible cohort; indeed, we observed that HPV prevalence increased with age (from $0 \%$ in the vaccine-eligible cohort to $12.3 \%$ in the pre-screening cohort and $19.7 \%$ in the screening cohort).

Our data showed a higher prevalence of HPV infection in females in the vaccineeligible cohort $(23.1 \%)$ and in males in the screening cohort $(19.7 \%)$. These findings are in agreement with those of a systematic review of the prevalence of genital HPV in men over 18 years of age, in which this prevalence was seen to peak in older men, but not in older women [35].

Ten years after the introduction of HPV vaccination for the female population, HPV-16 is still the most frequently observed genotype [36]. However, in our vaccine-eligible cohort, the most frequent genotype was HPV-52, which, in the pre-vaccine era was the second most frequent genotype after HPV-16 [36-38]. Notably, the frequency of HPV-52 was twice that of HPV-16. As HPV-52 is one of the types contained in the 9vHPV vaccine formulation, a reduction could be expected in the coming years.

It is noteworthy that a reduction in the number of HR-HPV and in the circulation of $\mathrm{HPV}$ vaccine types $(2 \mathrm{v}, 4 \mathrm{vHPV})$ was observed in the vaccine-eligible cohort in comparison with previous studies conducted in the same area in the pre-vaccine era [36,39]. No vaccine types $(2 v, 4 v, 9 v H P V)$ were found in males belonging to this cohort. Furthermore, it is important to point out that, as the vaccine-eligible cohort consisted of women with unknown vaccination status and unvaccinated males, the circulation of vaccine-preventable genotypes was expected.

In the other cohorts, the frequency of HPV vaccine types $(2 \mathrm{v}, 4 \mathrm{v}, 9 \mathrm{vHPV})$ increased with age in both sexes, but the preventable fraction remained around $90 \%$. These data suggest that catch-up programs should be implemented in order to vaccinate young women and young men beyond the 12-year-old cohort. The highest prevalence of vaccine types was observed in the screening cohort, especially in the male population, and this finding underlines the importance of including men in immunization programs. 


\section{Conclusions}

In this study, we observed an overall prevalence of genital HPV infection of $19 \%$, which was higher in females than in males. In the female population, ten years after the start of the national immunization program, we observed a reduction in the prevalence of vaccine types and also in the number of circulating genotypes, especially in the vaccine-eligible cohort. The absence of vaccine types in the male vaccine-eligible cohort could be evidence of a herd effect, despite suboptimal vaccination coverage (about $70 \%$ with three doses).

None of the men in our study had been vaccinated (the male vaccination program started in 2017 for 12-year-olds); our data are therefore essential to understanding the future effects of vaccination in this population.

The limit of this study is that the number of subjects enrolled was not large enough to be fully representative of the Italian population, and hence to precisely assess the impact of vaccination in Italy. However, this was a pilot study to evaluate the suitability of urine sampling in a monitoring context and in a larger population.

Our study highlights the importance of vaccinating both women and men in order to achieve good vaccination coverage and to protect males from HPV-related diseases. It also underlines the importance of including catch-up vaccination for women up to age 26 in the national immunization program, an approach that could be implemented by taking advantage of the Pap test call.

Author Contributions: Conceptualization, C.F. and S.B.; methodology, S.B. and D.C.; formal analysis, C.F., D.C., S.B., M.G.; investigation, D.A., D.P., S.S., F.P., A.A.; resources, E.T., D.P., I.G.; data curation, M.G.; writing-original draft preparation, C.F., S.B. and D.A.; writing—review and editing, M.G., A.A., F.P., D.P., S.S., E.T.; supervision, D.A., D.P., E.T., I.G.; funding acquisition, E.T., D.P. All authors have read and agreed to the published version of the manuscript.

Funding: This research received no external funding.

Institutional Review Board Statement: The study was conducted according to the guidelines of the Declaration of Helsinki and approved by the Institutional Review Board (or Ethics Committee) of Liguria Region (LHU) Genoa, Italy (protocol code n. 44/12, approved on 7 June 2017).

Informed Consent Statement: Informed consent was obtained from all subjects involved in the study

Data Availability Statement: The data presented in this study are available on request from the corresponding author.

Acknowledgments: The authors of this paper would like to thank Bernard Patrick for revising the English of the text.

Conflicts of Interest: The authors declare no conflict of interest.

\section{References}

1. Satterwhite, C.L.; Torrone, E.; Meites, E.; Dunn, E.F.; Mahajan, R.; Ocfemia, M.C.; Su, J.; Xu, F.; Weinstock, H. Sexually transmitted infections among US women and men: Prevalence and incidence estimates, 2008. Sex. Transm. Dis. 2013, 40, 187-193. [CrossRef]

2. WHO. A Cervical Cancer-Free Future: First-Ever Global Commitment to Eliminate a Cancer. Available online: https://www.wh o.int/news/item/17-11-2020-a-cervical-cancer-free-future-first-ever-global-commitment-to-eliminate-a-cancer (accessed on 15 December 2020).

3. Petca, A.; Borislavschi, A.; Zvanca, M.E.; Petca, R.C.; Sandru, F.; Dumitrascu, M.C. Non-sexual HPV transmission and role of vaccination for a better future (Review). Exp. Ther. Med. 2020, 20, 186. [CrossRef] [PubMed]

4. Bzhalava, D.; Eklund, C.; Dillner, J. International standardization and classification of human papillomavirus types. Virology 2015, 476, 341-344. [CrossRef] [PubMed]

5. Van Doorslaer, K.; Li, Z.; Xirasagar, S.; Maes, P.; Kaminsky, D.; Liou, D.; Sun, Q.; Kaur, R.; Huyen, Y.; McBride, A.A. The Papillomavirus Episteme: A major update to the papillomavirus sequence database. Nucleic Acids Res. 2017, 45, D499-D506. [CrossRef] [PubMed]

6. Muñoz, N.; Bosch, F.X.; de Sanjosé, S.; Herrero, R.; Castellsagué, X.; Shah, K.V.; Snijders, P.J.; Meijer, C.J. International Agency for Research on Cancer Multicenter Cervical Cancer Study Group. Epidemiologic classification of human papillomavirus types associated with cervical cancer. N. Engl. J. Med. 2003, 348, 518-527. [CrossRef]

7. Walboomers, J.M.; Jacobs, M.V.; Manos, M.M.; Bosch, F.X.; Kummer, J.A.; Shah, K.V.; Snijders, P.J.; Peto, J.; Meijer, C.J.; Muñoz, N. Human papillomavirus is a necessary cause of invasive cervical cancer worldwide. J. Pathol. 1999, 189, 12-19. [CrossRef] 
8. Moscicki, A.B.; Schiffman, M.; Kjaer, S.; Villa, L.L. Chapter 5: Updating the natural history of HPV and anogenital cancer. Vaccine 2006, 24 (Suppl. 3), S3/42-S3/51. [CrossRef] [PubMed]

9. Ljubojevic, S.; Skerlev, M. HPV-associated diseases. Clin. Dermatol. 2014, 32, 227-234. [CrossRef] [PubMed]

10. Yanofsky, V.R.; Patel, R.V.; Goldenberg, G. Genital warts: A comprehensive review. J. Clin. Aesthet. Dermatol. 2012, 5, 25-36.

11. Sichero, L.; Ferreira, S.; López, R.V.M.; Mello, B.P.; Costa, V.; El-Achkar, V.N.R.; Carlos, R.; Ribeiro-Silva, A.; Pignatari, S.; Kaminagakura, E.; et al. Prevalence of human papillomavirus 6 and 11 variants in recurrent respiratory papillomatosis. J. Med. Virol. 2020. [CrossRef]

12. de Oliveira, C.M.; Fregnani, J.H.T.G.; Villa, L.L. HPV Vaccine: Updates and Highlights. Acta Cytol. 2019, 63, 159-168. [CrossRef] [PubMed]

13. Trucchi, C.; Costantino, C.; Restivo, V.; Bertoncello, C.; Fortunato, F.; Tafuri, S.; Amicizia, D.; Martinelli, D.; Paganino, C.; Piazza, M.F.; et al. Immunization Campaigns and Strategies against Human Papillomavirus in Italy: The Results of a Survey to Regional and Local Health Units Representatives. Biomed. Res. Int. 2019, 2019, 6764154. [CrossRef]

14. Paavonen, J.; Naud, P.; Salmerón, J.; Wheeler, C.M.; Chow, S.N.; Apter, D.; Kitchener, H.; Castellsague, X.; Teixeira, J.C.; Skinner, S.R.; et al. Efficacy of human papillomavirus (HPV)-16/18 AS04-adjuvanted vaccine against cervical infection and precancer caused by oncogenic HPV types (PATRICIA): Final analysis of a double-blind, randomised study in young women. Lancet 2009, 374, 301-314. [CrossRef]

15. ECDC. Guidance on HPV Vaccination in EU Countries: Focus on Boys, People Living with HIV and 9-Valent HPV Vaccine Introduction. Available online: https://www.ecdc.europa.eu/en/publications-data/guidance-hpv-vaccination-eu-focus-boys -people-living-hiv-9vHPV-vaccine (accessed on 15 December 2020).

16. Istituto Superiore di Sanità. Strategie Vaccinali per Hpv. Available online: https://www.epicentro.iss.it/hpv/Strategie-Vaccini (accessed on 15 December 2020).

17. National Vaccination Plan (PNPV) 2017-2019. Available online: http://www.salute.gov.it/portale/vaccinazioni/dettaglioCont enutiVaccinazioni.jsp?lingua=italiano\&id=4828\&area $=$ vaccinazioni\&menu=vuoto (accessed on 15 December 2020).

18. Sinisgalli, E.; Bellini, I.; Indiani, L.; Sala, A.; Bechini, A.; Bonanni, P.; Boccalini, S. HPV vaccination for boys? A systematic review of economic studies. Epidemiol. Prev. 2015, 39 (Suppl. 1), 1-158.

19. Crochard, A.; Luyts, D.; di Nicola, S.; Gonçalves, M.A. Self-reported sexual debut and behavior in young adults aged 18-24 years in seven European countries: Implications for HPV vaccination programs. Gynecol. Oncol. 2009, 115, S7-S14. [CrossRef] [PubMed]

20. Panatto, D.; Amicizia, D.; Trucchi, C.; Casabona, F.; Lai, P.L.; Bonanni, P.; Boccalini, S.; Bechini, A.; Tiscione, E.; Zotti, C.M.; et al. Sexual behaviour and risk factors for the acquisition of human papillomavirus infections in young people in Italy: Suggestions for future vaccination policies. BMC Public Health 2012, 12, 623. [CrossRef] [PubMed]

21. Tanzi, E.; Bianchi, S.; Fasolo, M.M.; Frati, E.R.; Mazza, F.; Martinelli, M.; Colzani, D.; Beretta, R.; Zappa, A.; Orlando, G. High performance of a new PCR-based urine assay for HPV-DNA detection and genotyping. J. Med. Virol. 2013, 85, 91-98. [CrossRef] [PubMed]

22. IARC. Biological Agents, Human Papillomaviruses, IARC Monogr. Eval. Carcinog. Risks to Humans. 2012, Volume 100B, pp. 255-313. Available online: https:/ / publications.iarc.fr/Book-And-Report-Series/Iarc-Monographs-On-The-Identification-Of -Carcinogenic-Hazards-To-Humans/Biological-Agents-2012 (accessed on 15 December 2020).

23. HPV Information Centre. Available online: https://hpvcentre.net/ (accessed on 15 December 2020).

24. Dean, A.G.; Sullivan, K.M.; Soe, M.M. OpenEpi: Open Source Epidemiologic Statistics for Public Health. Available online: https:/ / www.openepi.com/Menu/OE_Menu.htm (accessed on 15 December 2020).

25. Centers for Disease Control and Prevention. Genital HPV Infection-CDC Fact Sheet. 2004. Available online: https://www.um healthpartners.com/wp-content/uploads/2016/09/hpvEN.pdf (accessed on 15 December 2020).

26. Giambi, C. Stato di Avanzamento Della Campagna Vaccinale per 1'HPV: Dati di Copertura Vaccinale al 30/06/2012-Rapporto Semestrale. 2013. Available online: http:/ / www.epicentro.iss.it/problemi/hpv/pdf/Aggiornamento_HPV_30062012_validat o.pdf (accessed on 15 December 2020).

27. Schmitt, M.; Bravo, I.G.; Snijders, P.J.; Gissmann, L.; Pawlita, M.; Waterboer, T. Bead-based multiplex genotyping of human papillomaviruses. J. Clin. Microbiol. 2006, 44, 504-512. [CrossRef] [PubMed]

28. Nordfors, C.; Vlastos, A.; Du, J.; Ahrlund-Richter, A.; Tertipis, N.; Grün, N.; Romanitan, M.; Haeggblom, L.; Roosaar, A.; Dahllöf, G.; et al. Human papillomavirus prevalence is high in oral samples of patients with tonsillar and base of tongue cancer. Oral Oncol. 2014, 50, 491-497. [CrossRef] [PubMed]

29. Dalianis, T.; Grün, N.; Koch, J.; Vlastos, A.; Tertipis, N.; Nordfors, C.A.; Wendt, M.; Romanitan, M.; Bersani, C.; Munck-Wikland, E.; et al. Human papillomavirus DNA and p16(INK4a) expression in hypopharyngeal cancer and in relation to clinical outcome, in Stockholm, Sweden. Oral Oncol. 2015, 51, 857-861. [CrossRef]

30. Dehlendorff, C.; Sparén, P.; Baldur-Felskov, B.; Herweijer, E.; Arnheim-Dahlström, L.; Ploner, A.; Uhnoo, I.; Kjaer, S.K. Effectiveness of varying number of doses and timing between doses of quadrivalent HPV vaccine against severe cervical lesions. Vaccine 2018, 36, 6373-6378. [CrossRef] [PubMed]

31. Cho, H.W.; Ouh, Y.T.; Hong, J.H.; Min, K.J.; So, K.A.; Kim, T.J.; Paik, E.S.; Lee, J.W.; Moon, J.H.; Lee, J.K. Comparison of urine, self-collected vaginal swab, and cervical swab samples for detecting human papillomavirus (HPV) with Roche Cobas HPV, Anyplex II HPV, and RealTime HR-S HPV assay. J. Virol. Methods 2019, 269, 77-82. [CrossRef] [PubMed] 
32. World Health Organization. Human papillomavirus vaccines: WHO position paper. Biologicals 2009, 37, 338-344. [CrossRef]

33. Orlando, G.; Tanzi, E.; Rizzardini, G.; Chatenoud, L.; Zanchetta, N.; Esposito, S.; Tisi, G.; Fasolo, M.; Bosari, S.; Boero, V.; et al. Modifiable and Non-Modifiable Factors Related to HPV Infection and Cervical Abnormalities in Women at High Risk: A Cross-sectional Analysis from the VALHIDATE Study. Ann. Virol. Res. 2016, 2, 1013.

34. World Health Organization. Electronic address: Sageexecsec@who.int. Human papillomavirus vaccines: WHO position paper, May 2017-Recommendations. Vaccine 2017, 35, 5753-5755. [CrossRef]

35. Smith, J.S.; Gilbert, P.A.; Melendy, A.; Rana, R.K.; Pimenta, J.M. Age-specific prevalence of human papillomavirus infection in males: A global review. J. Adolesc. Health 2011, 48, 540-552. [CrossRef] [PubMed]

36. Panatto, D.; Amicizia, D.; Tanzi, E.; Bianchi, S.; Frati, E.R.; Zotti, C.M.; Lai, P.L.; Bechini, A.; Rossi, S.; Gasparini, R. Prevalence of human papillomavirus in young Italian women with normal cytology: How should we adapt the national vaccination policy? BMC Infect. Dis. 2013, 13, 575. [CrossRef] [PubMed]

37. Howell-Jones, R.; Bailey, A.; Beddows, S.; Sargent, A.; de Silva, N.; Wilson, G.; Anton, J.; Nichols, T.; Soldan, K.; Kitchener, H.; et al. Multi-site study of HPV type-specific prevalence in women with cervical cancer, intraepithelial neoplasia and normal cytology, in England. Br. J. Cancer 2010, 103, 209-216. [CrossRef] [PubMed]

38. Schmeink, C.E.; Massuger, L.F.; Lenselink, C.H.; Quint, W.G.; Witte, B.I.; Berkhof, J.; Melchers, W.J.; Bekkers, R.L. Prospective follow-up of 2065 young unscreened women to study human papillomavirus incidence and clearance. Int. J. Cancer 2013, 133, 172-181. [CrossRef]

39. Orlando, G.; Fasolo, M.; Mazza, F.; Ricci, E.; Esposito, S.; Frati, E.; Zuccotti, G.V.; Cetin, I.; Gramegna, M.; Rizzardini, G.; et al. Risk of cervical HPV infection and prevalence of vaccine-type and other high-risk HPV types among sexually active teens and young women (13-26 years) enrolled in the VALHIDATE study. Hum. Vaccin. Immunother. 2014, 10, 986-994. [CrossRef] [PubMed] 